\title{
KETERSEDIAAN GURU DAN SARANA PRASARANA PJOK SMA DAN SMK SE-KECAMATAN GEROKGAK KABUPATEN BULELENG
}

\author{
Putu Panji Sulaksana ${ }^{1}$, I Nyoman Kanca. ${ }^{2}$, Made Agus Wijaya ${ }^{3}$ \\ Prodi Pendidikan Jasmani Kesehatan dan Rekreasi \\ Jurusan Pendidikan Olahraga \\ Fakultas Olahraga dan Kesehatan \\ Universitas Pendidikan Ganesha \\ e-mail: putupanjisulaksana08@gmail.com ${ }^{1}$, nyoman.kanca@undiksha.ac.id ${ }^{2}$, \\ wijaya.madeagus@undiksha.ac.id ${ }^{3}$
}

\begin{abstract}
Abstrak
Penelitian ini bertujuan untuk memperoleh data empiris ketersediaan guru dan sarana prasarana PJOK SMA dan SMK se-Kecamatan Gerokgak Kabupaten Buleleng. Jumlah populasi penelitian ini yaitu 7 sekolah. Penelitian ini adalah penelitian deskriptif yang menggambarkan suatu hal secara langsung dengan metode survei. Instrumen yang digunakan dalam penelitian ini adalah PDPJOI. Dari hasil penelitian didapatkan hasil sebagai berikut : 1) untuk ketersediaan guru di 7 sekolah berjumlah 15 orang guru dengan kualifikasi akademik S1 Penjaskesrek. 2) untuk ketersediaan sarana dan prasarana, SMA N 1 Gerokgak dengan total skor 180, SMA N 2 Gerokgak dengan total skor 109, MAN Buleleng dengan total skor 135, SMK N 1 Gerokgak dengan total skor 91, SMK PGRI Gerokgak dengan total skor 122, SMK Istiqlal dengan total skor 77, dan SMK Nusa Dua dengan total skor 122 sarana dan prasarana. Berdasarkan analisa data dan pembahasan dapat disimpulkan bahwa : (1). ketersediaan guru PJOK SMA dan SMK seKecamatan Gerokgak termasuk kategori "sangat baik" (2). Sarana dan prasarana PJOK SMA dan SMK se-Kecamatan Gerokgak termasuk kategori "cukup". Dengan demikian untuk pihak terkait agar senantiasa memperhatikan ketersediaan guru dan sarana prasarana demi kelancaran suatu pembelajaran secara maksimal.
\end{abstract}

Kata kunci: Ketersediaan, Guru, Sarana dan prasarana

\begin{abstract}
This study aims to obtain empirical data on the availability of teachers and infrastructure for PJOK SMA and SMK in Gerokgak District, Buleleng Regency. The population of this research is 7 schools. This research is a descriptive study that describes something directly with the survey method. The instrument used in this study was PDPJOI. From the research results obtained the following results: 1) for the availability of teachers in 7 schools totaling 15 teachers with academic qualifications of S1 Penjaskesrek. 2) for the availability of facilities and infrastructure, SMA N 1 Gerokgak with a total score of 180, SMA N 2 Gerokgak with a total score of 109, MAN Buleleng with a total score of 135, SMK N 1 Gerokgak with a total score of 91, SMK PGRI Gerokgak with a total score of 122, SMK Istiqlal with a total score of 77, and SMK Nusa Dua with a total score of 122 facilities and infrastructure. Based on data analysis and discussion, it can be concluded that: (1). the availability of PJOK SMA and SMK teachers in Gerokgak District is in the "very good" category (2). The facilities and infrastructure of PJOK SMA and SMK in Gerokgak District are categorized as "adequate". Thus for related parties to always pay attention to the availability of teachers and infrastructure for the smooth running of a maximum learning.
\end{abstract}

Key words: Availability, teacher, facilities and infrastructure.

\section{PENDAHULUAN}

$\mathrm{Di}$ Indonesia banyak terdapat sekolah negeri maupun swasta yang berperan penting untuk mencerdaskan peserta didik untuk kemajuan bangsa Indonesia kedepannya. Di dalam Undang Undang Republik Indonesia No. 20 tahun 2003 pasal 1 ayat 1 tentang 
Sistem Pendidikan Nasional menyebutkan Pendidikan adalah usaha sadar dan terencana untuk mewujudkan suasana belajar dan proses pembelajaran agar peserta didik secara aktif mengembangkan potensi dirinya untuk memiliki kekuatan spiritual keagamaan, pengendalian diri, kepribadian, kecerdasan, akhlak mulia, serta keterampilan yang diperlukan dirinya, masyarakat, bangsa dan negara. Begitu pula dengan pendidikan jasmani yang tidak lepas dari menumbuhkan atau mengembangkan keterampilan dan potensi peserta didik. Abdul(Samsudin,2008:2) menjelaskan bahwa pendidikan jasmani adalah suatu proses pendidikan seseorang sebagai perorangan atau anggota masyarakat yang dilakukan secara sadar dan sistematik melalui berbagai kegiatan jasmani, kemampuan dan keterampilan, kecerdasan dan perkembangan watak, serta kepribadian yang harmonis dalam rangka pembentukan manusia indonesia berkualitas berdasarkan pancasila (Cholik Mutohir,1992). Didalam pendidikan jasmani terdapat proses pembelajaran yang tidak dapat dipisahkan yang didalamnya terdapat interaksi guru dan peserta didik. Berbicara mengenai proses pembelajaran, tentu tidak terlepas dari ketersediaan guru dan sarana dan prasarana yang dimiliki oleh sekolah. Menurut Undang -Undang Republik Indonesia nomor 14 tahun 2005 pasal 1 ayat 1 tentang guru dan dosen menyebutkan guru adalah pendidik professional dengan tugas utama mendidik , mengajar, membimbing, mengarahkan, melatih, menilai, dan mengevaluasi peserta didik pada pendidikan anak usia dini jalur pendidikan formal, pendidikan dasar, dan pendidikan menengah. Peran guru dalam proses pembelajaran sangatlah penting, karena dalam proses pembelajaran berhasil tidaknya suatu proses pembelajaran tergantung bagaimana guru tersebut mampu mengelola dan mengorganisir dalam proses pembelajaran. Faktor guru sangat berpengaruh pada kualitas pembelajaran karena guru merupakan alat sebagai pendukung pembelajaran yang mempersiapkan dan mengelola proses pembelajaran. Ada 10 keterampilan guru dalam proses belajar mengajar yang harus dikusai yaitu : 1) Keterampilan membuka pelajaran, 2) Keterampilan menjelaskan, 3) Keterampilan bertanya, 4) Keterampilan memberikan penguatan, 5) Keterampilan memberi motivasi, 6) Keterampilan menggunakan media pembelajaran,7)Keterampilan membimbing diskusi kelompok kecil, 8) Keterampilan mengadakan variasi, 9) Keterampilan mengajar perorangan dan kelompok kecil, dan 10) Keterampilan menutup pelajaran.

Dalam hal ini guru diharapkan dapat melaksanakan keterampilan tersebut dan menyiapkan sarana dan prasarana untuk menunjang proses belajar mengajar sehingga tujuan pembelajaran bisa tercapai dengan baik. Ketersediaan guru dan sarana prasarana di Indonesia khususnya di sekolah harus memiliki tenaga pendidik yang professional dan sarana prasarana yang memadai sehingga proses belajar mengajar terlaksana dengan baik. Menurut peraturan pemerintah Nomor 19 Tahun 2005 Pasal 1 ayat 1 tentang Standar Nasional Pendidikan menyebutkan bahwa Standar nasional pendidikan adalah kriteria minimal tentang sistem pendidikan di seluruh wilayah hukum Negara Kesatuan Republik Indonesia dan pasal 1 ayat 8 menyebutkan bahwa Standar sarana dan prasarana adalah standar nasional pendidikan yang berkaitan dengan kriteria minimal tentang ruang belajar, tempat berolahraga, tempat beribadah, perpustakaan, laboratorium, bengkel kerja, tempat bermain, tempat berkreasi dan berekreasi, serta sumber belajar lain, yang diperlukan untuk menunjang proses pembelajaran, termasuk penggunaan teknologi informasi dan komunikasi.

Ketersediaan guru dan sarana prasarana di Bali terutama di 
Kecamatan Gerokgak harus memadai sehingga proses belajar mengajar bisa berjalan dengan baik. Namun pada kenyataannya masih banyak keterbatasan guru dan sarana prasarana yang memenuhi keperluan pendidikan.

Keterbatasan tenaga pendidik maupun sarana dan prasarana pembelajaran pendidikan jasmani akan membuat proses pembelajaran menjadi kurang lancar dan tujuan pembelajaran tidak sepenuhnya tercapai karena kurangnya sarana pendidikan jasmani dapat menghambat memanipulasi gerak pada peserta didik. Peserta didik akan mengantri dalam pergantian menggunakan peralatan pendidikan jasmani, peserta didik akan menjadi bosan dan peserta didik banyak beristirahat. Ini akan mengakibatkan kebugaran tidak akan tercapai. Hal tersebut harus dihindari demi kebugaran peserta didik, maka sarana pendidikan jasmani harus disesuaikan dengan jumlah peserta didik dan mengkondisikannya dengan baik agar pembelajaran pendidikan jasmani dapat berjalan dengan lancar dan mendukung Maka dari itu peran guru dan sarana prasarana pembelajaran pendidikan jasmani sangatlah penting dan saling berkaitan. Dengan adanya METODE

Penelitian ini adalah penelitian deskriptif kuantitatif. Menurut Kanca (2010:57) penelitian deskriptif adalah penelitian yang bertujuan untuk mendeskripsikan secara sistematis, faktual dan akurat terhadap suatu populasi, atau daerah tertentu, mengenai sifat-sifat dan fakta-fakta tertentu. guru yang baik dan sarana prasarana yang mencukupi, sangat membantu dalam proses pembelajaran pendidikan jasmani sehingga peserta didik menjadi lebih maksimal dalam menerima materi pembelajaran. Peserta didik lebih sering dalam melakukan berbagai keterampilan dan aktivitas di dalam proses pembelajaran sehingga tujuan pembelajaran pendidikan jasmani tercapai dengan baik.

Hasil pra observasi salah satu Sekolah di Gerokgak kabupaten Buleleng ditemukan bahwa ketersediaan guru dan sarana prasana pendidikan jasmani masih belum mencukupi sehingga proses pembelajaran menjadi kurang baik.

Berdasarkan permasalahanpermasalahan yang telah diuraikan di atas mendorong penulis untuk mengadakan penelitian lebih dalam tentang bagaimana sarana prasarana pendidikan jasmani di SMA dan SMK seKecamatan Gerokgak kabupaten Buleleng. Oleh karena itu, Peneliti berusaha mencari fakta yang ada di lapangan untuk dapat diambil kesimpulan terhadap ketersediaan guru dan sarana prasarana PJOK di SMA dan SMK se-Kecamatan Gerokgak kabupaten Buleleng.

Penelitian ini menggunakan populasi. Menurut (Kanca,2010:19) Populasi adalah keseluruhan atau himpunan obyek dengan ciri yang sama. Populasi dari penelitian ini yaitu seluruh SMA dan SMK se-Kecamatan Gerokgak Kabupaten Buleleng yang berjumlah 7 sekolah.

Tabel 1 Nama Sekolah SMA dan SMK se-Kecamatan Gerokgak

\begin{tabular}{lll}
\hline No & \multicolumn{1}{c}{ Nama Sekolah } & \multicolumn{1}{c}{ Alamat } \\
\hline 1 & SMA N 1 Gerokgak & Ds. Sanggalangit \\
2 & SMA N 2 Gerokgak & Ds. Pemuteran \\
3 & MAN Buleleng & Ds. Patas \\
4 & SMK N 1 Gerokgak & Ds. Banyupoh \\
5 & SMK PGRI 1 Gerokgak & Ds. Patas \\
6 & SMK Istiqlal & Ds. Patas \\
\hline
\end{tabular}




\begin{tabular}{lll}
\hline 7 & SMK Nusa Dua & Ds. Sumberkima \\
\hline
\end{tabular}

Menurut Sugiono (2018:145) instrumen penelitian adalah suatu alat yang digunakan mengukur fenomena alam maupun sosial yang diamati. Dan penelitian ini menggunakan instrumen PDPJOI (Pangkalan Data Pendidikan Jasmani Olahraga Indonesia).

\section{HASIL DAN PEMBAHASAN}

Pada hasil penelitian ini dijabarkan mengenai temuan-temuan yang diperoleh oleh peneliti selama penelitian di SMA dan SMK seKecamatan Gerokgak Kabupaten Buleleng untuk menjawab permasalahan yang telah diajukan pada pendahulan sebelumnya, yaitu mengenai ketersediaan guru dan Sarana Prasarana PJOK melalui instrument PDPJOI. Maka dari itu diperoleh hasil sebagai berikut :

Tabel 2 Rekap Data SMA dan SMK se-Kecamatan Gerokgak

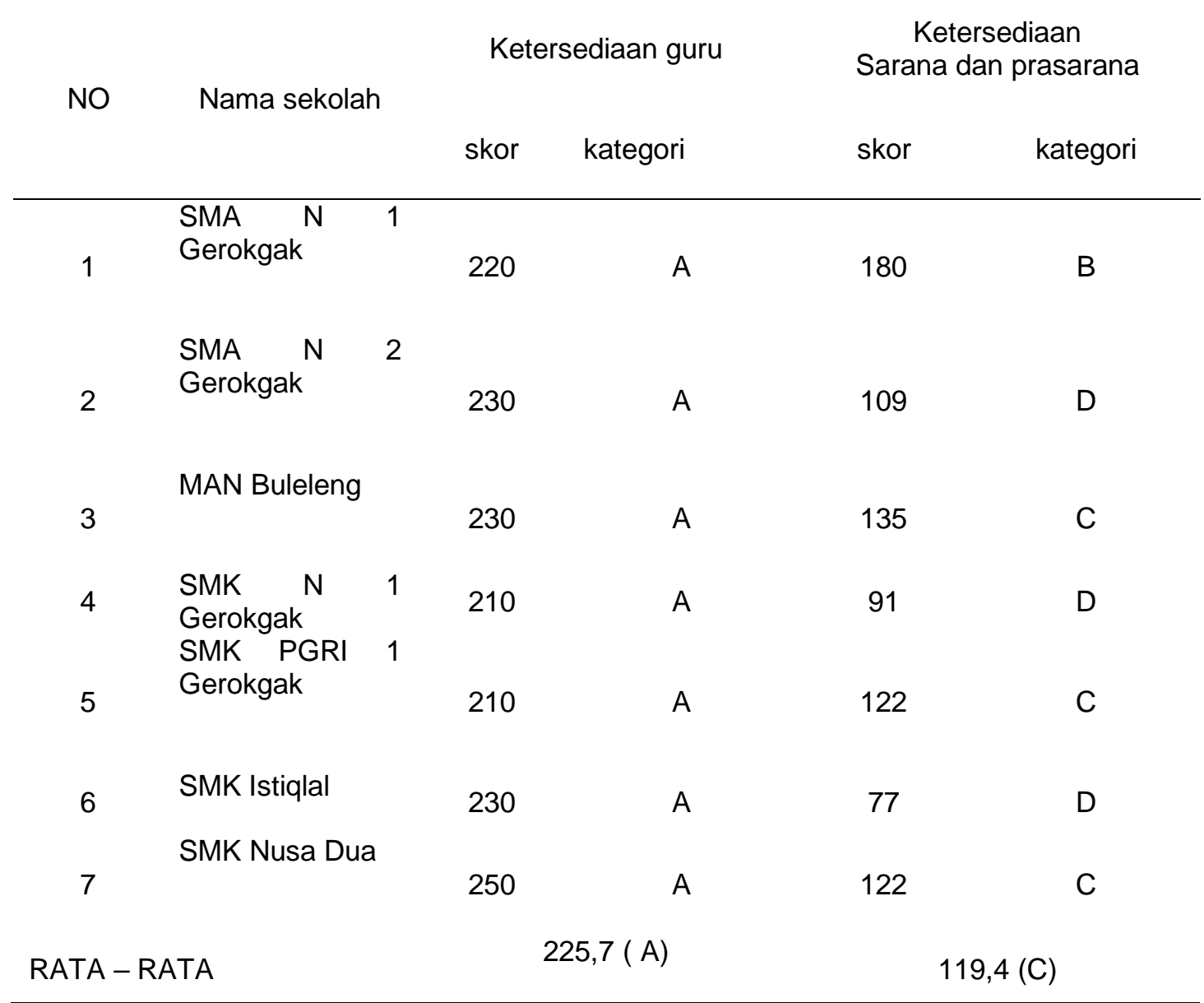

Berdasarkan tabel 2 diatas dapat diketahui bahwa ketersediaan guru PJOK SMA dan SMK se-Kecamatan Gerokgak termasuk kategori "A" dengan rata-rata 225,7 dan untuk ketersediaan sarana prasarana termasuk kategori " $\mathrm{C}$ " dengan rata-rata 119,4.

\section{PEMBAHASAN}

Pada penelitian ini dilakukan untuk mengetahui ketersediaan guru dan sarana prasarana PJOK SMA dan SMK se-Kecamatan Gerokgak. Berdasarkan hasil olah data yang telah diuraikan oleh peneliti di atas maka dapat dijelaskan sebagai berikut : 
Untuk ketersediaan guru rata -rata keseluruhan termasuk kategori " $A$ " dengan skor 225,7 dengan rincian sebagai berikut:

a. 7 sekolah termasuk kategori "A" (SMA N 1 Gerokgak, SMA N 2 Gerokgak, MAN Buleleng, SMK N 1 Gerokgak, SMK PGRI 1 Gerokgak, SMK Istiqlal, dan SMK Nusa Dua), karena di sekolah tersebut terdapat guru PNS dan tetap dengan kualifikasi akademik S1 PJKR.

\section{Ketersediaan Sarana dan \\ Prasarana}

Untuk sarana dan prasarana secara keseluruhan termasuk kategori "C" dengan skor 119,4 dengan rincian sebagai berikut :

a. 1 sekolah termasuk kategori "B" (SMA N 1 Gerokgak), karena sekolah tersebut memiliki sarana dan prasarana yang memadai dengan jumlah peserta didik di sekolah tersebut.

b. 3 sekolah termasuk kategori "C" (MAN Buleleng, SMK PGRI 1 Gerokgak, dan SMK Nusa Dua), karena jumlah sarana dan prasarana yang dimiliki di sekolah tersebut cukup sebanding dengan jumlah peserta didik di sekolah tersebut untuk proses belajar mengajar.

c. 3 sekolah termasuk kategori "D" ( SMA N 2 Gerokgak, SMK N 1 Gerokgak, dan SMK Istiqlal), sekolah yang mendapat kategori " $D$ " jumlah sarana dan prasarana kurang memadai untuk proses kegiatan belajar mengajar sehingga peserta didik akan kesulitan untuk mengikuti pembelajaran maupun untuk meningkatkan potensi diri yang dimiliki oleh peserta didik tersebut.

\section{SIMPULAN DAN SARAN}

Berdasarkan hasil dari

pembahasan sesuai dengan rumusan masalah dan tujuan penelitian, maka dapat disimpulkan bahwa :

1. Ketersediaan guru PJOK SMA dan SMK se-Kecamatan Gerokgak Kabupaten Buleleng termasuk kategori "A" karena guru yang ada di sekolah tersebut sudah berstatus PNS dan pegawai tetap dengan kualifikasi akademik S1 PJKR.
2. Ketersediaan sarana prasarana PJOK SMA dan SMK se-Kecamatan Gerokgak Kabupaten Buleleng termasuk kategori "C" karena luas lahan dan sarana prasarana cukup sebanding dengan jumlah peserta didik dan penggunaan sarana sering digunakan oleh peserta didik sehingga banyak alat yang rusak terutama bola sepak, bulu tangkis dan bola voli, namun masih sedikit ditemukan sarana yang dimodifikasi. Dan masih terdapat prasarana yang rusak karena kurang pemeliharaan.

\section{DAFTAR PUSTAKA}

Anas Sudijono. (2012). Pengantar Statistik Pendidikan. Jakarta: Rajawali Pers.

Biki,N.2018. survei sarana prasarana PJOK berbasis kurikulum di sma se-kabupaten Gorontalo Utara. ttps://repository.ung.ac.id/skripsi/sh ow/832413002/survei-saranaprasarana-pjok-berbasiskurikulum-di-sma-se-kabupatengorontalo-utara.html

Depdiknas, 2005. Peraturan pemerintah nomor 14 Tahun 2005, Tentang guru dan dosen, Jakarta:Depdiknas

Depdiknas, 2005, peraturan Pemerintah Nomor 19 Tahun 2005,tentang standar nasional pendidikan, Jakarta: Depdiknas

Undang-undang RI No.20 tahun 2003. Tentang sistem pendidikan nasional

Hamalik, Oemar .2001, proses belajar mengajar, Jakarta: Bumi Aksara

Kanca, I Nyoman. (2010). Metode Penelitian Pengajaran Pendidikan Jasmani dan Olahraga. Singaraja : Universitas Pendidikan Ganesha.

Permendiknas,2007, peraturan pemerintah nomor 24 tahun 
2007.tentang standar sarana dan prasarana, Permendiknas

Poerwanti, Yuni dkk, Pangkalan Data Pendidikan Jasmani dan Olahraga PDPJOI Tahun 2007. Jakarta : Kementrian Negara Pemuda dan Olahraga Republik Indonesia

Prasetya, R,P,E,Sudarso. 2019. Survei sarana dan prasarana pendidikan jasmani olahraga dan kesehatan di sma negeri se-kabupaten trenggalek.

https://jurnalmahasiswa.unesa.ac.i d/index.php/jurnal-pendidikanjasmani/article/view/26996

Rosdiani,2012, Model pembelajaran langsung dalam pendidikan jasmani dan kesehatan. Bandung: Alfabeta

Rusli,2000,strategi belajar mengajar pjokkes,Depdiknas
Samsudin. 2008. Pembelajaran Pendidikan Jasmani Olahraga dan Kesehatan. Jakarta: Litera.

Setiyoko,H.hari wisnu. 2019. Survei sarana dan prasarana pendidikan jasmani olahraga dan kesehatan di smp negeri se-kabupaten Pacitan. https://jurnalmahasiswa.unesa.ac.id/ind ex.php/jurnal-pendidikanjasmani/article/view/28241http://lib.unn es.ac.id/11046/

Suandi, I Nengah dkk. (2016). Pedoman Penulisan Karya IImiah. Singaraja: Undiksha press.

Sugiyono. (2018). Metode Penelitian Evaluasi. Yogyakarta: Yogyakarta: Alfabeta.

Sujarweni, Wiratna. (2018). Metodologi Penelitian. Cetakan Pertama. Yogyakarta : Pustakabaru press. 